\title{
Droplet digital PCR for detection and quantification of circulating tumor DNA in plasma of head and neck cancer patients
}

\author{
Joost H. van Ginkel ${ }^{1,2^{*}}$, Manon M. H. Huibers ${ }^{2}$, Robert J. J. van Es ${ }^{1,3}$, Remco de Bree ${ }^{3}$ and Stefan M. Willems ${ }^{2}$
}

\begin{abstract}
Background: During posttreatment surveillance of head and neck cancer patients, imaging is insufficiently accurate for the early detection of relapsing disease. Free circulating tumor DNA (ctDNA) may serve as a novel biomarker for monitoring tumor burden during posttreatment surveillance of these patients. In this exploratory study, we investigated whether low level ctDNA in plasma of head and neck cancer patients can be detected using Droplet Digital PCR (ddPCR).

Methods: TP53 mutations were determined in surgically resected primary tumor samples from six patients with high stage (II-IV), moderate to poorly differentiated head and neck squamous cell carcinoma (HNSCC).

Subsequently, mutation specific ddPCR assays were designed. Pretreatment plasma samples from these patients were examined on the presence of ctDNA by ddPCR using the mutation-specific assays. The $\mathrm{ddPCR}$ results were evaluated alongside clinicopathological data.
\end{abstract}

Results: In all cases, plasma samples were found positive for targeted TP53 mutations in varying degrees (absolute quantification of 2.2-422 mutational copies/ml plasma). Mutations were detected in wild-type TP53 background templates of 7667-156,667 copies/ml plasma, yielding fractional abundances of down to $0.01 \%$.

Conclusions: Our results show that detection of tumor specific TP53 mutations in low level ctDNA from HNSCC patients using $\mathrm{ddPCR}$ is technically feasible and provide ground for future research on ctDNA quantification for the use of diagnostic biomarkers in the posttreatment surveillance of HNSCC patients.

Keywords: Head and neck cancer, Circulating tumor DNA, Droplet digital PCR, TP53 mutations, Diagnostic biomarker

\section{Background}

Monitoring tumor response during posttreatment surveillance of head and neck cancer patients heavily relies on clinical examination supported by endoscopy and/or imaging (e.g. computerized tomography (CT), magnetic resonance imaging (MRI), or positron emission tomography (PET)). However, early detection of recurrent disease is challenging due to lymph nodal micrometastases and radiation or surgery induced fibrosis and

\footnotetext{
* Correspondence: j.h.vanginkel-2@umcutrecht.nl

'Department of Oral and Maxillofacial Surgery, University Medical Center Utrecht, Utrecht, The Netherlands

${ }^{2}$ Department of Pathology, University Medical Center Utrecht, Heidelberglaan 100, 3584 CX Utrecht, The Netherlands

Full list of author information is available at the end of the article
}

inflammation, obscuring residual or recurrent tumor tissue [1-3]. Accurate and timely detection of locoregional metastases and recurrent disease is pivotal as survival rates rapidly decline with late detection and delayed salvage surgery $[4,5]$. With recent developments in molecular diagnostics, the use of (blood-based) genetic biomarkers is growing in a wide variety of cancer types [6]. Cell free circulating tumor DNA (ctDNA), released into the bloodstream by apoptotic and necrotic tumor cells, harbor tumor-specific mutations [7]. These mutations can be detected in blood plasma from cancer patients by blood sampling, also known as "liquid biopsy" [8]. For head and neck cancer, research has been focused mainly on actionable oncogenic mutations such as PIK3CA and HRAS, hot-spot TP53 mutations, and 
HPV-related biomarkers to use as prognosticators or predictors for establishing and adjusting targeted therapy [9-12]. For similar purposes, transcriptional and epigenetic changes are studied substantially [13-15]. For the early detection of recurrent disease, early driver mutations in HNSCC such as TP53 mutations would be favorable to use as biomarkers, as these are likely to occur consistently throughout clonal evolution $[16,17]$, and are found to be most frequent and concordant in recurrent and metastatic HPV-negative tumors compared to mutations in other genes [18-22]. By targeting and quantifying early driver mutations in ctDNA, tumor burden could be monitored after treatment, facilitating earlier detection of asymptomatic residual and/or recurrent disease. Previous studies showed correlations between ctDNA levels and tumor dynamics during posttreatment monitoring in patients with various types of cancer [2326]. However, accurate detection of ctDNA in plasma is challenging, because ctDNA concentrations can be very low. This could greatly impair reliable and valid measurement of tumor dynamics. Highly sensitive Droplet Digital PCR (ddPCR) facilitates detection and quantification of low levels of ctDNA by partitioning DNA samples into 20,000 water-in-oil droplets [27]. In this exploratory study, we investigated whether detection and quantification of ctDNA in plasma from several head and neck squamous cell carcinoma (HNSCC) patients using ddPCR is technically feasible.

\section{Methods}

\section{Patients and samples}

Six patients (median age 60.5 [42-77] years) with histologically confirmed HPV-negative HNSCC were selected retrospectively for analysis of archived primary tumor samples and presurgically obtained blood samples. Patient selection was based on TNM stage (stage II or higher) and availability of blood plasma samples in our biobank. Additional clinicopathological and radiological data were collected from hospital charts of selected patients (Table 1; Fig. 1).

\section{Sample workup}

All primary tumor samples were acquired from formalin fixed paraffin embedded (FFPE) incisional or excisional biopsy specimens, microscopically containing $>30 \%$ tumor cells. In order to reveal TP53 mutation status of primary tumor samples, targeted next-generation sequencing (NGS) was performed using the Ion Torrent ${ }^{\mathrm{m}}$ PGM platform (Thermo Fisher Scientific, Waltham, MA, USA), as previously described [28]. NGS was based on the Cancer Hotspot Panel v2+ (Thermo Fisher Scientific, Waltham, MA, USA), covering TP53 exons 2-10 [29]. All blood samples were collected in $10 \mathrm{ml}$ $\mathrm{K}_{2}$ EDTA blood collection tubes (BD Vacutainer, Franklin Lakes, NJ, USA). Prior to archiving, centrifugation took place for $10 \mathrm{~min}$ at $800 \mathrm{~g}$ (Rotina 380, Hettich, Germany), after which supernatant plasma was aliquoted in $1 \mathrm{ml}$ portions and stored at $-80{ }^{\circ} \mathrm{C}$ until DNA isolation. Storage time of patient FFPE and corresponding plasma samples varied from 4 months to 9 years.

Plasma samples were thawed and DNA was immediately isolated from $2 \mathrm{ml}$ of plasma using QIAamp Circulating Nucleic Acid (NA) kit (Qiagen, Hilden, Germany) according to the manufacturer's instructions. Isolated plasma samples were eluted in $50 \mu$ l elution buffer as provided with the kit and stored at $4{ }^{\circ} \mathrm{C}$ until ddPCR analysis. Positive control samples, containing both wildtype (WT) and mutant (MT) DNA, were created for all patients by isolating tumor DNA from the primary tumor FFPE samples using COBAS DNA Sample Preparation Kit (Roche, Basel, Switzerland) according to manufacturer's instructions. After quantity measurement of isolated DNA samples with a Qubit fluorometer using the dsDNA HS (High Sensitivity) Assay Kit (Thermo Fisher Scientific), cfDNA was diluted to $10 \mathrm{ng} / \mathrm{ul}$ using purified water. For each assay, no template controls (NTC) were used to control for environmental contamination, and wild-type-only (WT-only) samples were used in order to estimate false-positive rates. Five WTonly samples were created by isolating plasma DNA

Table 1 Summary of patient and tumor characteristics

\begin{tabular}{|c|c|c|c|c|c|c|c|c|c|c|}
\hline Patient ID & Sex & $\begin{array}{l}\text { Smoking } \\
\text { (pack years) }\end{array}$ & $\begin{array}{l}\text { Alcohol } \\
\text { (units/day) }\end{array}$ & Biopsy type & TNM-stage & Tumor site $^{a}$ & Differentiation grade & $\begin{array}{l}\text { Max diameter primary } \\
\text { tumor }(\mathrm{mm})\end{array}$ & $\begin{array}{l}\text { Growth } \\
\text { type }\end{array}$ & $\begin{array}{l}\text { Vascular } \\
\text { invasion }\end{array}$ \\
\hline P1 & M & 0 & 8 & Excisional & T4aN1M0 & OSCC & Moderate & 40 & NS & No \\
\hline P2 & M & 0 & 0 & Excisional & T4aN2cM0 & oscc & Poor & 72 & NS & Yes \\
\hline P3 & $\mathrm{F}$ & 0 & 0 & Excisional & T2NOMx & oscC & Moderate & 32 & Unknown & Yes \\
\hline P4 & M & Unknown & 1 & Excisional & T4aN2bM0 & oscc & Moderate & 46 & S & No \\
\hline P5 & M & 49 & 12 & Excisional & T4aN1M0 & OSCC & Moderate/poor & 37 & Unknown & No \\
\hline P6 & $\mathrm{F}$ & 42 & 2 & Incisional & T3N2cMO & OPSCC & Unknown & 13 & N/A & No \\
\hline
\end{tabular}

${ }^{a}$ OSCC Oral Squamous Cell Carcinoma, OPSCC Oropharyngeal Squamous Cell Carcinoma

${ }^{\mathrm{b}}$ NS Non Spiculated, S Spiculated 

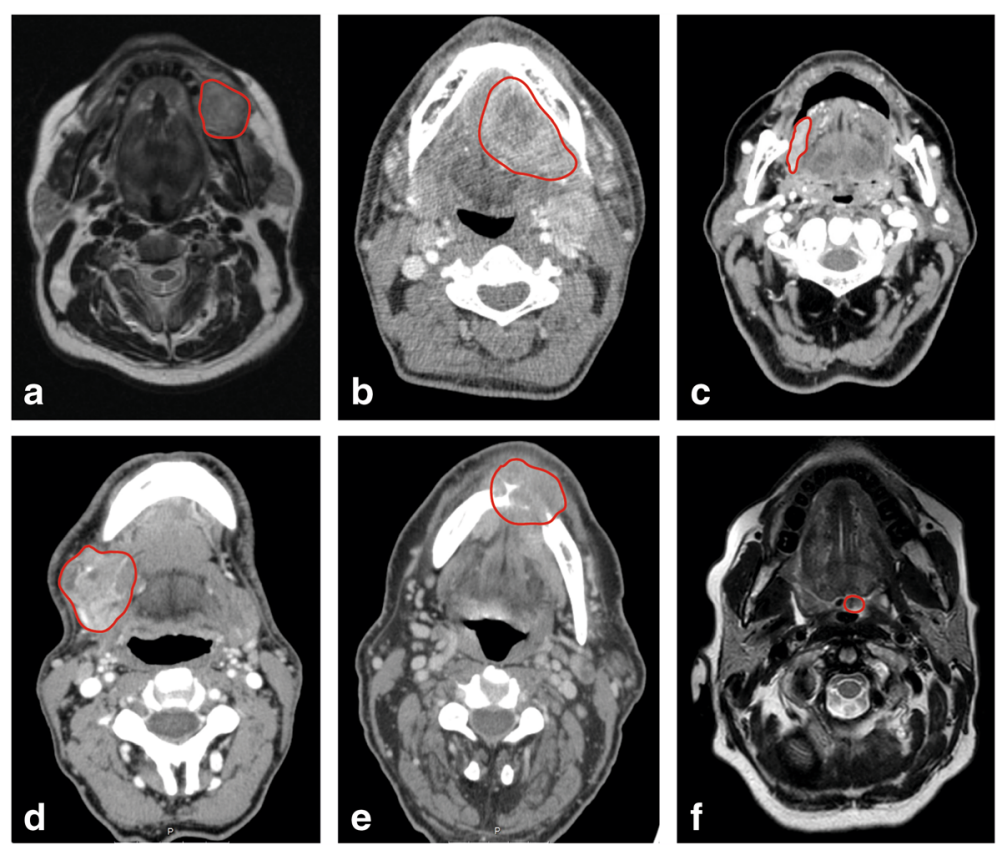

Fig. 1 Primary tumors of six patients encircled in red. a Axial T1 MRI image of a tumor in the left mandible of patient 1. b Axial ceCT image of a tumor in the floor of mouth of patient 2. c Axial ceCT image of a tumor in the right lateral tonque of patient 3. $\mathbf{d}$ Axial ceCT image of a tumor in the right mandible/floor of mouth/tongue of patient 4. e Axial ceCT image of a tumor in the floor of mouth in patient 5. f Axial T1 MRI image of tumor in left mid tongue base of patient 6. ceCT = contrast enhanced computed tomography

from anonymous healthy individuals using the QIAamp Circulating NA kit.

\section{ddPCR}

The plasma samples from all 6 patients were analyzed for TP53 point mutations, identified in the primary tumor tissue by NGS. MT and WT TP53 sequences were used as DNA template for designing ddPCR (BioRad Laboratories, Hercules, CA, USA) assays following the MIQE guidelines (Additional file 1: Table S1) [30]. DdPCR reaction volumes of $22 \mu \mathrm{l}$ were prepared, consisting of $13 \mu \mathrm{l}$ mastermix (11 $\mu$ l Supermix for Probes [no deoxyuridine triphosphate], $1 \mu \mathrm{l}$ of primer/probe mix for both MT and WT TP53), and $9 \mu \mathrm{lcfDNA}$ sample of patient plasma. The NTCs contained $9 \mu$ of purified water instead of cfDNA sample. The WT-only samples contained 1-7 ul of cfDNA. From the PCR reaction mixture, $20 \mu \mathrm{l}$ was used for droplet generation. Droplet Digital PCR was performed using the QX200 ddPCR system according to manufacturer's instructions (Bio-Rad Laboratories). QuantaSoft v1.7.4.0917 (Bio-Rad Laboratories) software was used for data analysis.

Prior to plasma sample testing, thermal gradient experiments were performed on FFPE samples in order to determine optimal amplification conditions during thermal cycling for each assay independently. Based on clearest separation of negative and positive droplet clusters, thermal cycling conditions for all 6 assays were set at $95{ }^{\circ} \mathrm{C}$ for $10 \mathrm{~min}$ ( 1 cycle), $94{ }^{\circ} \mathrm{C}$ for $30 \mathrm{~s}$ and $55^{\circ}$ $\mathrm{C}$ for $60 \mathrm{~s}$ ( 55 cycles), and infinite hold at $12{ }^{\circ} \mathrm{C}$. To ensure experiment quality, wells with total droplet counts of less than 10,000 would be considered invalid and excluded from analysis. The positive control samples were used to verify assay performance and facilitate thresholding in fluorescence values. Additionally, positive control samples were validated by comparing the fractional abundance (FA) in FFPE samples to NGS mutation frequencies. False-positive rate estimation was determined by performing 5 experiments for each assay using the WT-only samples, where total amounts of detected MT-positive droplets determined thresholds above which positive droplets in patient samples were to be considered as true positive.

\section{Post-analysis}

For each patient, plasma was analyzed in duplicate. Therefore, PCR results of patients samples were based on the mean of estimated target DNA concentrations

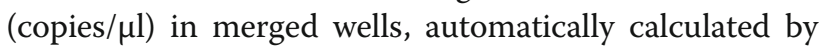
manufacturer software. Correction for false positivity was performed by virtually subtracting the amount of MT-false-positive droplets from the amount of MTpositive droplets detected in the patients sample with the corresponding assays. Subsequently, absolute sample concentrations were (re)calculated as described in 
Additional file 1: Eq. S1. Relative quantification was defined as the FA of MT to total (WT + MT) copies.

\section{Results}

\section{Assay validation}

In all six patients, TP53 mutations were detected in FFPE by both NGS and ddPCR (Additional file 1: Table S1 and Additional file 2: Figure S1). FA of MT copies ranged from $6.1-71.7 \%$ in positive control samples, compared to NGS mutant percentages of $7-70 \%$. False-positive rate estimation was necessary to determine aspecific MT signal (Additional file 1: Table S2). One MT-false-positive droplet was detected in the WT-only sample control series for assay 1 and 3, establishing a true positivity threshold of $>1$ MT-positive droplet for these assays (Additional file 3: Figure S2 and Additional file 4: Figure S3). For the remaining assays, no MT-falsepositive droplets were detected in the WT-only samples. WT-false-positive droplets for all used assays in NTCs ranged from 0 to 10 droplets. No MT-positive droplets were detected in any of the NTC samples (Additional file 5: Figure S4).

\section{ctDNA quantification}

The amount of ctDNA was quantified and analyzed in blood plasma samples from all 6 patients (Table 2). MT copies of TP53 were detected in plasma samples from all patients (Fig. 2a), ranging from 0.04 to 7.60 copies/ $\mu \mathrm{l}$ ddPCR mix and 1-181 MT-positive droplets in merged wells (Fig. 2b). When corrected for MT-false-positive droplets, plasma ctDNA concentrations ranged from 2.2 to 422 copies/ml plasma (Fig. 3a). MT copies were detected in WT backgrounds of $138-2821$ copies/ $\mu \mathrm{l}$, yielding FA of MT copies of $0.01-5.2 \%$ (Fig. 3b).

\section{Discussion}

Our study shows that quantification of rare target mutations in ctDNA in plasma from HNSCC patients using ddPCR is technically feasible. Highly sensitive detection methods like digital PCR are needed in order to detect rare MT targets within high concentrations of WT background [31]. WT background size (i.e. concentration of
WT cfDNA) can strongly vary over time for each patient individually, depending on multiple factors. For instance, patient's physical status (e.g. inflammation, post-traumatic, post-exercise, chronic illness), as well as pre-analytical technical procedures (e.g. white blood cell lysis caused by whole blood transportation and processing) appear to affect cfDNA concentrations [32-35]. Increased cfDNA concentration causes dilution of ctDNA, which could lower the accuracy of rare MT fragment detection. Therefore, pre-analytical steps should be most optimally in lowering background DNA; e.g. blood plasma instead of serum is preferred as source for ctDNA, as the amount of cfDNA in serum can be 2-4 times higher than that in plasma [36].

It has been shown for various applications that $\mathrm{ddPCR}$ is capable of rare target DNA quantification with higher precision and accuracy compared to quantitative PCR [27, 37-39]. Although we did not perform quantitative PCR we found relative quantification measurements of MT copies down to $0.01 \%$. This falls within the potential dynamic range for absolute quantification of rare target DNA within a 100,000-fold of WT background as previously demonstrated [40, 41]. Similar quantification results were reported in a study where TP53 mutations were identified in plasma using another PCR-based detection method in $88 \%$ of HPV-negative HNSCC patients $(n=22)$ with MT fractions varying between 0.016 and $2.9 \%$ [42]. We also found large variability in MT quantification measurements among patient samples. This is consistent with previous mutation analysis of blood samples from HNSCC patients, in which MT TP53 fragments of $0-1500$ per $5 \mathrm{ml}$ plasma were targeted and detected by conventional PCR [43].

Variances in detected MT copies among patients can be the result of various (pre)analytical deficiencies and technical errors like plasma sample contamination from the environment. Furthermore, decreased DNA concentration due to prolonged storage, poor sample quality, subsampling during whole blood retrieval and/or centrifugation, inefficient DNA isolation from plasma samples, poor droplet handling leading to shredding or coalition of droplets, instrument artifacts, intrinsic PCR errors caused by PCR inhibition and/or minor mismatches

Table 2 Absolute and relative quantifications of MT and WT DNA in plasma samples from HNSCC patients

\begin{tabular}{|c|c|c|c|c|c|c|}
\hline \multirow{2}{*}{$\begin{array}{l}\text { Sample } \\
\text { ID }\end{array}$} & \multicolumn{3}{|c|}{ MT DNA concentration } & \multicolumn{2}{|c|}{ WT DNA concentration } & \multirow[t]{2}{*}{$F A_{\text {mut }}$} \\
\hline & Sample (copies/ul) & 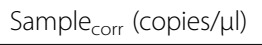 & Plasma (copies/ml) & 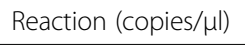 & Plasma (copies/ml) & \\
\hline P1 & 0.47 & 0.43 & 24 & 315 & 17,500 & $0.13 \%$ \\
\hline P2 & 7.60 & 7.60 & 422 & 138 & 7667 & $5.50 \%$ \\
\hline P3 & 0.17 & 0.16 & 8.9 & 158 & 8778 & $0.10 \%$ \\
\hline P4 & 1.79 & 1.79 & 99 & 2821 & 156,667 & $0.06 \%$ \\
\hline P5 & 0.37 & 0.37 & 21 & 380 & 21,167 & $0.10 \%$ \\
\hline P6 & 0.04 & 0.04 & 2.2 & 397 & 22,056 & $0.01 \%$ \\
\hline
\end{tabular}




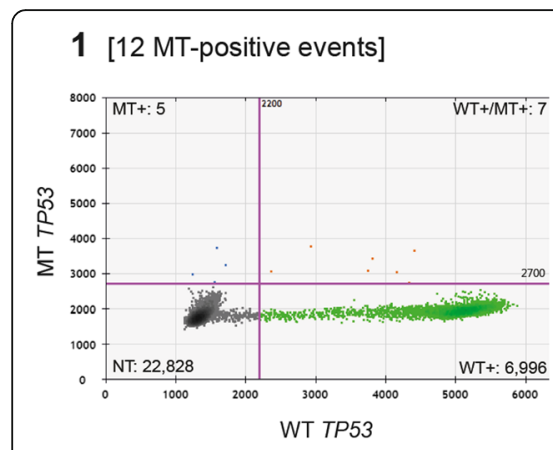

4 [53 MT-positive events]

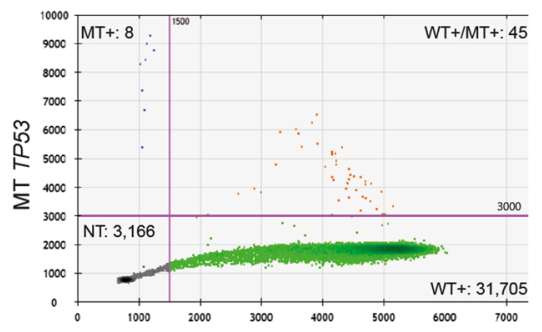

WT TP53

MT positive droplets WT positive droplets
2 [181 MT-positive events]

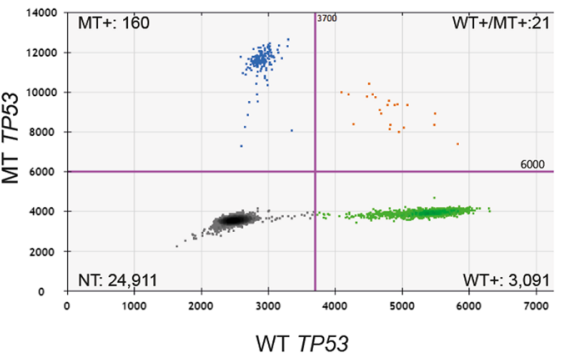

5 [10 MT-positive events]

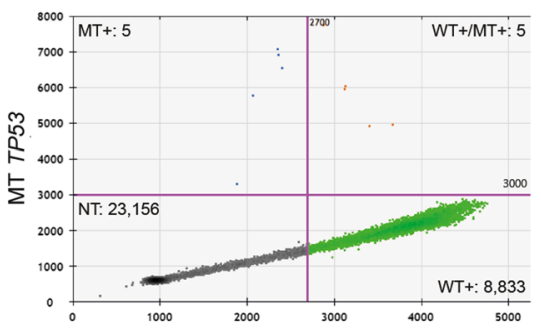

WT TP53

Total amount of droplets
3 [5 MT-positive events]

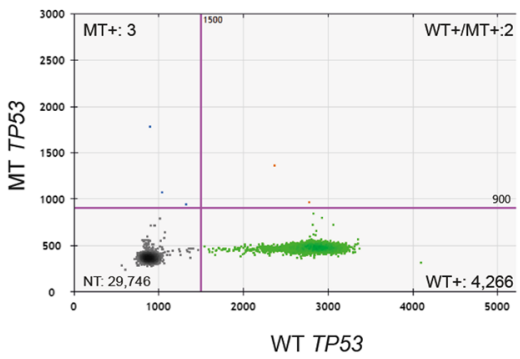

6 [1 MT-positive events]

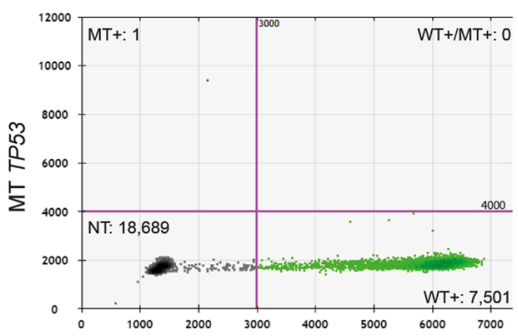

WT TP53

Fig. 2 2D-plots and amount of MT-positive droplets of ddPCR results of all six patients. a All diagrams (1-6) represent merged ddPCR results of duplicates of corresponding patient samples (1-6), showing MT-positive droplet clusters (blue dots), negative droplet clusters (dark grey dots), and MT/ WT-positive droplets (orange dots). The green dots represent WT-positive droplets, proving existence of cfDNA in the samples and satisfactory ddPCR conditions. Purple lines are manually placed thresholds for distinguishing positive and negative droplets, which were set at fluorescence values based on ddPCR results of FFPE samples. $\mathbf{b}$ The amount of MT-positive and negative droplets based on thresholds as placed in 2D-plots in (a)

between primer/probes and target molecules can all affect PCR results $[44,45]$.

During ddPCR post-analysis, manual threshold determination and stochastic sampling errors could directly lead to over- or underestimation of target copies, resulting in inaccurate quantification of results [46]. Furthermore, we know from previous validation experiences that fluorescence values of positive droplet clusters can vary inter-experiment, while assessing DNA samples derived from the same individual and using identical
ddPCR assays. The same holds true for ddPCR experiments on DNA samples derived from different plasma matrices and/or volumes, containing different PCR inhibitors [47]. These points concerning post-analysis need to be addressed in order to implement ddPCR for ctDNA quantification into clinical practice. Therefore each assay and each sample should be analyzed individually. Although we used FFPE for positive control samples for threshold placement and plasma from different individuals for false-positive rate estimation, samples were
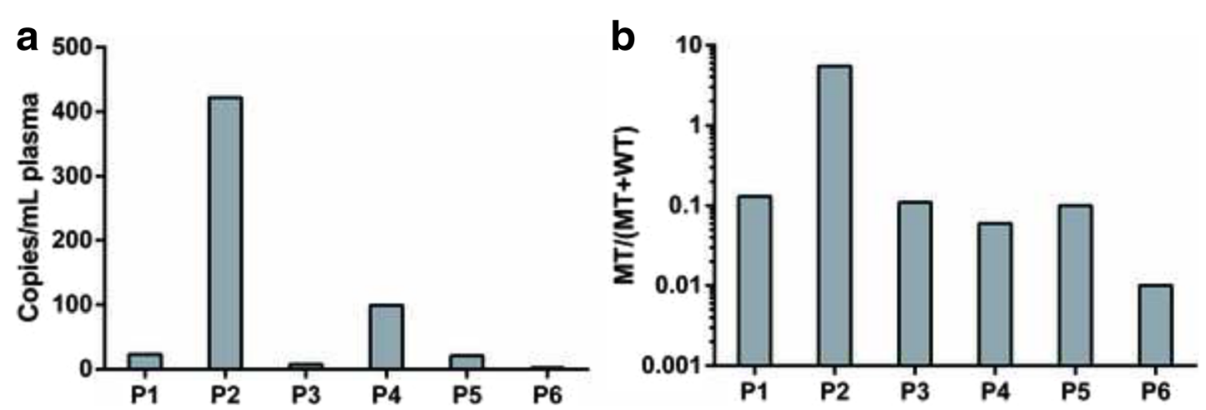

Fig. 3 DdPCR results of patients (P1-P6) showing absolute quantification of ctDNA concentrations in plasma (a), and log-scaled fractional abundances of MT copies from total amount of MT and WT copies as corrected for total DNA input (b) 
patient specific and of similar matrix of DNA source, respectively. In this way, plasma DNA composition from the patients was mimicked most realistically. Moreover, the alternative of using (spiked) series of artificially synthesized DNA oligonucleotides for creating control samples can provoke overestimation of PCR targets due to the high purity of these solutions. Eventually, interpretation of ddPCR results depends on the accuracy of ctDNA quantification which is determined by false positive rate estimation.

Several biological factors could affect ctDNA concentration. Especially tumor volume is of interest as it may reflect tumor burden and actual disease status through correlation with ctDNA concentration. Simultaneously, tumor characteristics such as histological grade, localization, growth pattern, growth rate, and degree of vascularization possibly complicate reliable monitoring of tumor burden by ctDNA quantification, as these factors might affect ctDNA release into the bloodstream all differently [44, 48]. However, in a series of 117 patients with primary HNSCC, no significant correlation was found between gender, tumor stage, site, and plasma ctDNA concentration detected by touchdown PCR [49]. Interestingly, in our study, the highest amount of ctDNA was detected in plasma from the patient that harbored the largest tumor diameter of all six included patients. This tumor also had a poor histological differentiation grade with vascular invasion. At the other end, the lowest amount of ctDNA was detected in plasma from the patient with the smallest tumor diameter and without vascular invasion. However, we studied and compared plasma samples retrieved at one time point from a rather small group of high-stage HNSCC patients with presumably greater tumor burden and plasma ctDNA concentrations.

Therefore, serial ctDNA quantification in clinical patients diagnosed with primary HNSCC of all stages is needed to clarify its significance for posttreatment disease monitoring and the possible advantages of its specific application with respect to early tumor detection in relation to current clinical diagnostics [50]. Tumor heterogeneity could further complicate monitoring tumor burden through ctDNA detection, because intratumoral heterogeneity of the primary tumor induces branched tumor evolution of subclonal populations harboring different molecular alterations [51]. This could lead to increased clonal heterogeneity between primary tumor and matched metastatic or recurrent tumors, risking mistargeting of ctDNA. However, as early driver TP53 mutations show high concordance between primary and recurrent and/or metastatic tumors, these may hold promise as most reliable targets for ctDNA detection and for early tumor detection of HNSCC recurrences [21].

\section{Conclusion}

The detection of tumor specific TP53 mutations in ctDNA from HNSCC using a ddPCR is technically feasible and provide ground for further research on ctDNA quantification to be used as a diagnostic biomarker in the posttreatment surveillance of HNSCC patients.

\section{Additional files}

\begin{abstract}
Additional file 1: Table S1-2. NGS data, PCR assays, and Assay validation. Eq. S1 Equation used for manual conversion of target copies to plasma concentrations. (DOCX $24 \mathrm{~kb}$ )
\end{abstract}

Additional file 2: Figure S1. DdPCR results of 6 different MT TP53 assays on positive control (FFPE) samples of all 6 patients are shown. The MT-positive clusters (blue dots) and MTMT-positive clusters (orange dots) are clearly separated from the negative droplet clusters (dark grey dots) and WT-positive droplet clusters. Thresholds are placed manually. (TIFF $1834 \mathrm{~kb}$ )

Additional file 3: Figure S2. 2D-plots with the amounts of droplets of $\mathrm{ddPCR}$ results in healthy individuals using assay 1-6. All threshold are placed using exact values as derived from the 2D-plots in Additional file 2: Figure S1. The plots represent merged results of plasma samples from 4 to 5 different healthy individuals for each assay. MT+ MT-positive droplets, WT+ WT-positive droplets, MT+MT+ MT/WT-positive droplets, NT No template droplets. (TIFF $1255 \mathrm{~kb}$ )

Additional file 4: Figure S3. DdPCR results for all 6 patients side-by-side with the WT-only samples from healthy individuals. All patient samples are shown in duplicate. In order to estimate the false positive rate for patient samples, plasma samples from five different healthy individuals were used. In the samples from healthy individuals 3 and 1 used during validation of assay 2 and assay 6, less than 10,000 droplets were detected. Therefore, these results were excluded from false positive estimation for the corresponding assays. (TIFF $6899 \mathrm{~kb}$ )

Additional file 5: Figure S4. NTC samples showing minimal environmental contamination with WT-positive droplets. No MT-positive droplets were detected in any of the NTC samples. (TIFF 3242 kb)

\section{Abbreviations}

$C T$ : Computer tomography; ctDNA: Circulating tumor DNA; ddPCR: Droplet digital polymerase chain reaction; FA: Fractional abundance; FFPE: Formalin fixed paraffin embedded; HNSCC: Head and neck squamous cell carcinoma; HPV: Human papilloma virus; MRI: Magnetic resonance imaging; MT: Mutant; NGS: Next-generation sequencing; PET: Positron emission tomography; WT: Wild type

\section{Acknowledgements}

R. de Weger and J. van Kuik helped establishing ddPCR in our lab. R. Noorlag initiated acquisition of biomaterials.

\section{Funding}

Sequencing and ddPCR assays were funded by the Dutch Cancer Society (clinical fellowship: 2011-4964) on behalf of SW.

\section{Availability of data and materials}

Supporting data can be found in Additional file 1. Raw data generated and analyzed during this study is electronically available upon request by contacting the corresponding author of this manuscript.

\section{Authors' contributions}

JG, MH and SW conceived and designed the study. $\mathrm{MH}, \mathrm{SW}, \mathrm{RB}$, and RE were involved in drafting and revising the manuscript critically for important intellectual content. RB and RE collected and provided biomaterials and clinicopathological data. JG and $\mathrm{MH}$ carried out the experiments. JG and $\mathrm{MH}$ analyzed and interpreted the data. JG wrote the manuscript. All authors read and approved the final manuscript. 


\section{Competing interests}

The authors declare that they have no competing interests.

\section{Consent for publication}

According to Dutch legislation, no informed consent to publish clinical information is required as only anonymous data was used [52].

\section{Ethics approval and consent to participate}

All patients were treated in University Medical Center Utrecht. According to Dutch national ethical guidelines, no ethical approval to use leftover material for scientific purposes is required, as the use of anonymous leftover material is part of the treatment agreement with patients at the University Medical Center Utrecht [53]. Administrative permission was received from the hospital for accessing the hospital medical records for research purposes.

\section{Publisher's Note}

Springer Nature remains neutral with regard to jurisdictional claims in published maps and institutional affiliations.

\section{Author details}

'Department of Oral and Maxillofacial Surgery, University Medical Center Utrecht, Utrecht, The Netherlands. ${ }^{2}$ Department of Pathology, University Medical Center Utrecht, Heidelberglaan 100, 3584 CX Utrecht, The Netherlands. ${ }^{3}$ Department of Head and Neck Surgical Oncology, UMC Utrecht Cancer Center, University Medical Center Utrecht, Utrecht, The Netherlands.

\section{Received: 6 January 2017 Accepted: 12 June 2017}

\section{Published online: 19 June 2017}

\section{References}

1. Ferlito A, Partridge M, Brennan J, Hamakawa H. Lymph node micrometastases in head and neck cancer: a review. Acta Otolaryngol. 2001;121:660-5

2. de Bree $R$, van der Putten L, Brouwer J, Castelijns JA, Hoekstra OS, Leemans $C R$. Detection of locoregional recurrent head and neck cancer after (chemo)radiotherapy using modern imaging. Oral Oncol. 2009:45:386-93.

3. Muller J, Hullner M, Strobel K, Huber GF, Burger IA, Haerle SK. The value of (18) F-FDG-PET/CT imaging in oral cavity cancer patients following surgical reconstruction. Laryngoscope. 2015;125:1861-8.

4. Gleber-Netto FO, Braakhuis BJ, Triantafyllou A, Takes RP, Kelner N, Rodrigo $J P$, et al. Molecular events in relapsed oral squamous cell carcinoma: Recurrence vs. secondary primary tumor. Oral Oncol. 2015;51:738-44.

5. Yom SS, Machtay M, Biel MA, Sinard RJ, El-Naggar AK, Weber RS, et al. Survival impact of planned restaging and early surgical salvage following definitive chemoradiation for locally advanced squamous cell carcinomas of the oropharynx and hypopharynx. American Journal of Clinical OncologyCancer Clinical Trials. 2005:28:385-92.

6. Kalia M. Biomarkers for personalized oncology: recent advances and future challenges. Metabolism. 2015:64:S16-21.

7. Jahr S, Hentze H, Englisch S, Hardt D, Fackelmayer FO, Hesch RD, et al. DNA fragments in the blood plasma of cancer patients: Quantitations and evidence for their origin from apoptotic and necrotic cells. Cancer Res. 2001;61:1659-65.

8. Diaz LA Jr, Bardelli A. Liquid biopsies: genotyping circulating tumor DNA. J Clin Oncol. 2014;32:579-86.

9. Nemunaitis J, Clayman G, Agarwala SS, Hrushesky W, Wells JR, Moore C, et al. Biomarkers predict p53 gene therapy efficacy in recurrent squamous cell carcinoma of the head and neck. Clin Cancer Res. 2009:15:7719-25.

10. Lui WW, Hedberg ML, Li H, Vangara BS, Pendleton K, Zeng Y, et al. Frequent mutation of the PI3K pathway in head and neck cancer defines predictive biomarkers. Cancer Discov. 2013;3:761-9.

11. Ndiaye C, Mena M, Alemany $L$, Arbyn M, Castellsague $X$, Laporte $L$, et al. HPV DNA, E6/E7 mRNA, and p16INK4a detection in head and neck cancers: a systematic review and meta-analysis. Lancet Oncol. 2014;15:1319-31.

12. Koole $K$, Brunen $D$, van Kempen PM, Noorlag $R$, de Bree $R$, Lieftink $C$, et al FGFR1 Is a Potential prognostic biomarker and therapeutic target in head and neck squamous cell carcinoma. Clin Cancer Res. 2016:22:3884-93.

13. Arantes LMRB, de Carvalho AC, Melendez ME, Carvalho AL, Goloni-Bertollo EM. Methylation as a biomarker for head and neck cancer. Oral Oncol. 2014;50:587-92.
14. Noorlag R, van Kempen PMW, Moelans CB, de Jong R, Blok LER, Koole R, et al. Promoter hypermethylation using 24-gene array in early head and neck cancer Better outcome in oral than in oropharyngeal cancer. Epigenetics. 2014;9:1220-7.

15. Zhang M, Zhao LJ, Liang WQ, Mao ZP. Identification of microRNAs as diagnostic biomarkers in screening of head and neck cancer: a metaanalysis. Genet Mol Res. 2015;14:16562-76.

16. Boyle JO, Hakim J, Koch W, van der Riet P, Hruban RH, Roa RA, et al. The incidence of p53 mutations increases with progression of head and neck cancer. Cancer Res. 1993;53:4477-80.

17. Nees M, Homann N, Discher H, Andl T, Enders C, Herold-Mende C, et al. Expression of mutated p53 occurs in tumor-distant epithelia of head and neck cancer patients: a possible molecular basis for the development of multiple tumors. Cancer Res. 1993;53:4189-96.

18. Hedberg ML, Goh G, Chiosea SI, Bauman JE, Freilino ML, Zeng Y, et al. Genetic landscape of metastatic and recurrent head and neck squamous cell carcinoma. J Clin Invest. 2016:126:169-80.

19. Morris LG, Chandramohan R, West L, Zehir A, Chakravarty D, Pfister DG, et al The Molecular landscape of recurrent and metastatic head and neck cancers: insights from a precision oncology sequencing platform. JAMA Oncol. 2016;

20. Hiley C, de Bruin EC, McGranahan N, Swanton C. Deciphering intratumor heterogeneity and temporal acquisition of driver events to refine precision medicine. Genome Biol. 2014;15:453.

21. van Ginkel JH, de Leng WW, de Bree R, van Es RJ, Willems SM. Targeted sequencing reveals TP53 as a potential diagnostic biomarker in the posttreatment surveillance of head and neck cancer. Oncotarget. 2016;

22. Seiwert TY, Zuo ZX, Keck MK, Khattri A, Pedamallu CS, Stricker T, et al. Integrative and comparative genomic analysis of HPV-positive and HPV-negative head and neck squamous cell carcinomas. Clin Cancer Res. 2015;21:632-41.

23. Diehl F, Schmidt K, Choti MA, Romans K, Goodman S, Li M, et al. Circulating mutant DNA to assess tumor dynamics. Nat Med. 2008;14:985-90.

24. Dawson SJ, Tsui DWY, Murtaza M, Biggs H, Rueda OM, Chin SF, et al. Analysis of circulating tumor DNA to monitor metastatic breast cancer. N Engl J Med. 2013;368:1199-209.

25. Gray ES, Rizos H, Reid AL, Boyd SC, Pereira MR, Lo J, et al. Circulating tumor DNA to monitor treatment response and detect acquired resistance in patients with metastatic melanoma. Oncotarget. 2015;6:42008-18.

26. Reinert $T$, Scholer LV, Thomsen $R$, Tobiasen $H$, Vang S, Nordentoft I, et al. Analysis of circulating tumour DNA to monitor disease burden following colorectal cancer surgery. Gut. 2015;

27. Hindson CM, Chevillet JR, Briggs HA, Gallichotte EN, Ruf IK, Hindson BJ, et al. Absolute quantification by droplet digital PCR versus analog real-time PCR. Nat Methods. 2013;10:1003-5.

28. de Leng WW, Gadellaa-van Hooijdonk CG, Barendregt-Smouter FA, Koudijs MJ, Nijman I, Hinrichs JW, et al. Targeted Next generation sequencing as a reliable diagnostic assay for the detection of somatic mutations in tumours using minimal DNA amounts from formalin fixed paraffin embedded material. PLoS One. 2016:11:e0149405.

29. Hoogstraat M, Hinrichs JW, Besselink NJ, Radersma-van Loon JH, de Voijs CM, Peeters T, et al. Simultaneous detection of clinically relevant mutations and amplifications for routine cancer pathology. J Mol Diagn. 2015;17:10-8.

30. Huggett JF, Foy CA, Benes V, Emslie K, Garson JA, Haynes R, et al. The digital MIQE guidelines: minimum information for publication of quantitative digital PCR experiments. Clin Chem. 2013;59:892-902.

31. Qin Z, Ljubimov VA, Zhou C, Tong Y, Liang J. Cell-free circulating tumor DNA in cancer. Chin J Cancer. 2016:35:36.

32. Fleischhacker M, Schmidt B. Circulating nucleic acids (CNAs) and cancer-a survey. Biochim Biophys Acta. 2007;1775:181-232.

33. Rothwell DG, Smith N, Morris D, Leong HS, Li YY, Hollebecque A, et al. Genetic profiling of tumours using both circulating free DNA and circulating tumour cells isolated from the same preserved whole blood sample. Mol Oncol. 2016;10:566-74.

34. El Messaoudi S, Rolet F, Mouliere F, Thierry AR. Circulating cell free DNA: preanalytical considerations. Clin Chim Acta. 2013;424:222-30

35. Swarup V, Rajeswari MR. Circulating (cell-free) nucleic acids - a promising, non-invasive tool for early detection of several human diseases. FEBS Lett. 2007:581:795-9.

36. Jung M, Klotzek S, Lewandowski M, Fleischhacker M, Jung K. Changes in concentration of DNA in serum and plasma during storage of blood samples. Clin Chem. 2003;49:1028-9. 
37. Wang P, Jing F, Li G, Wu Z, Cheng Z, Zhang J, et al. Absolute quantification of lung cancer related microRNA by droplet digital PCR. Biosens Bioelectron. 2015;74:836-42.

38. Tang H, Cai Q, Li H, Hu P. Comparison of droplet digital PCR to real-time PCR for quantification of hepatitis B virus DNA. Biosci Biotechnol Biochem. 2016:1-6.

39. Ruelle J, Yfantis V, Duquenne A, Goubau P. Validation of an ultrasensitive digital droplet PCR assay for HIV-2 plasma RNA quantification. J Int AIDS Soc. 2014;17:19675.

40. Hindson BJ, Ness KD, Masquelier DA, Belgrader P, Heredia NJ, Makarewicz AJ, et al. High-throughput droplet digital PCR system for absolute quantitation of DNA copy number. Anal Chem. 2011;83:8604-10.

41. Pinheiro LB, Coleman VA, Hindson CM, Herrmann J, Hindson BJ, Bhat S, et al. Evaluation of a droplet digital polymerase chain reaction format for DNA copy number quantification. Anal Chem. 2012;84:1003-11.

42. Wang Y, Springer S, Mulvey CL, Silliman N, Schaefer J, Sausen M, et al. Detection of somatic mutations and HPV in the saliva and plasma of patients with head and neck squamous cell carcinomas. Sci Transl Med. 2015;7:293ra104

43. Bettegowda C, Sausen M, Leary RJ, Kinde I, Wang Y, Agrawal N, et al. Detection of circulating tumor DNA in early- and late-stage human malignancies. Sci Transl Med. 2014;6:224ra224.

44. Ignatiadis M, Lee M, Jeffrey SS. Circulating Tumor Cells and Circulating Tumor DNA: Challenges and Opportunities on the Path to Clinical Utility. Clin Cancer Res. 2015;21:4786-800.

45. Sozzi G, Roz L, Conte D, Mariani L, Andriani F, Verderio P, et al. Effects of prolonged storage of whole plasma or isolated plasma DNA on the results of circulating DNA quantification assays. J Natl Cancer Inst. 2005;97:1848-50

46. Trypsteen W, Vynck M, De Neve J, Bonczkowski P, Kiselinova M, Malatinkova E, et al. ddpcRquant: threshold determination for single channel droplet digital PCR experiments. Anal Bioanal Chem. 2015;407:5827-34.

47. Devonshire AS, Whale AS, Gutteridge A, Jones G, Cowen S, Foy CA, et al. Towards standardisation of cell-free DNA measurement in plasma: controls for extraction efficiency, fragment size bias and quantification. Anal Bioanal Chem. 2014:406:6499-512.

48. Nygaard AD, Holdgaard PC, Spindler KLG, Pallisgaard N, Jakobsen A. The correlation between cell-free DNA and tumour burden was estimated by PET/CT in patients with advanced NSCLC. Br J Cancer. 2014;110:363-8.

49. Coulet F, Blons H, Cabelquenne A, Lecomte T, Lacourreye O, Brasnu D, et al. Detection of plasma tumor DNA in head and neck squamous cell carcinoma by microsatellite typing and p53 mutation analysis. Cancer Res. 2000;60:707-11.

50. Heitzer E, Ulz P, Geigl JB. Circulating tumor DNA as a liquid biopsy for cancer. Clin Chem. 2015:61:112-23.

51. Burrell RA, McGranahan N, Bartek J, Swanton C. The causes and consequences of genetic heterogeneity in cancer evolution. Nature. 2013, 501:338-45.

52. Netherlands. Medical research involving human subjects act. Bull Med Ethics. 1999;No. 152:13-8.

53. van Diest PJ. For and against - No consent should be needed for using leftover body material for scientific purposes - For. Br Med J. 2002;325:648-9.

\section{Submit your next manuscript to BioMed Central and we will help you at every step:}

- We accept pre-submission inquiries

- Our selector tool helps you to find the most relevant journal

- We provide round the clock customer support

- Convenient online submission

- Thorough peer review

- Inclusion in PubMed and all major indexing services

- Maximum visibility for your research

Submit your manuscript at www.biomedcentral.com/submit
Biomed Central 